\section{As tensões destruidoras do proceso de cambio na Bolívia}

\section{Destructive tensions of proceso de cambio in Bolivia}

\author{
DOI: 10.5752/P.2317-773X.2017v5.n1.p63
}

Fabio Luis Barbosa dos Santos ${ }^{1}$

Recebido em: 2017-07-07

Aprovado em: 2017-10-04
1. Doutor em História Econômica. Professor do Departamento de Relações Internacionais da Universidade Federal de São Paulo (UNIFESP). Contato: faboroso@gmail.com

\title{
RESUMo
}

Este artigo analisa o proceso de cambio desencadeado pela eleição de Evo Morales na Bolívia em 2005. Após contextualizar a ascensão política do líder cocalero, localizo acontecimentos que ocasionaram fissuras em sua base popular, principalmente após sua reeleição em 2009. A partir deste ponto, analiso diferentes segmentos que sustentam o governo e as políticas que lastreiam este apoio, com o propósito de identificar a natureza do projeto do MAS. Minha hipótese é que os conflitos que fraturaram a base social do governo não constituem "tensões criativas da revolução", como propõe o vice-presidente García Linera, mas indicam um desgaste que se evidenciou na derrota do referendo por um quarto mandato para Morales em fevereiro de 2016. Em termos regionais, a análise do processo social em um dos países que protagonizou a onda progressista sul-americana, enseja uma problematização da natureza dos vínculos regionais estimulados neste contexto, em particular pelas gestões petistas no Brasil.

Palavras-chave: Bolívia; Morales; Proceso de cambio; movimentos sociais; onda progressista.

\begin{abstract}
This article analyses the proceso de cambio unleashed by the election of Evo Morales in 2005 in Bolivia. After contextualizing the political ascension of the cocalero leader, I reffer the circunstances that have fractured its popular base, mostly after his reelection in 2009. From that point on, I analyse different social groups that sustain the government and the policies that underline that support. The main purpose is to identify the nature of MAS project. My hypothesis is that the conflicts that have split the government's social base do not constitute the "revolution's creative tensions" as argued by vice president García Linera, but they played a major role defeating the government's proposal for a fourth mandate to Morales, submited to a referendum in February 2016. As the social process of a protagonist country of the South American pink tide is analyzed, the nature of regional bonds fostered particularly by PT governments in Brazil is problematized.
\end{abstract}

Keywords: Bolivia; Morales; Proceso de cambio; social movements; pink tide. 
2. Para uma discussão sobre governos progressistas sul-americanos, consultar Webber \& Carr: 2013; sobre o bem viver, Acosta: 2016
Introdução

Desde seu primeiro momento, o governo Morales foi interpretado internacionalmente como uma gestão progressista, somando-se à onda de presidentes eleitos na América Latina em reação ao neoliberalismo desde a posse de Hugo Chávez em 1999. As credenciais eram fortes: a origem pobre e as feições indígenas, em um país marcado pelo racismo; a associação à folha de coca, que se converteu em símbolo de autodeterminação cultural; o antagonismo aos Estados Unidos, por este mesmo motivo; a identificação com a mãe-terra, o bem viver e outros valores de raiz indígena; a trajetória como liderança sindical rural; as circunstâncias da ascensão à presidência, colada um uma extensa mobilização que reverteu medidas neoliberais e derrubou dois presidentes ${ }^{2}$.

No plano regional, a gestão Morales se incorporou à ALBA-TCP e cultivou laços de proximidade com gestões consideradas progressistas, principalmente na Venezuela e Brasil. No caso brasileiro, esta proximidade está sedimentada em importantes vínculos comerciais, que se solidificaram desde a construção do gasoduto ligando os dois países nos anos 1990. Atualmente, o Brasil é o principal importador da Bolívia e o seu segundo exportador.

$\mathrm{Na}$ esfera política, a percepção prevalente das gestões Morales como desafiadora da ordem neoliberal tem sido evocada no Brasil, inclusive, para criticar os governos petistas pela esquerda. Por exemplo, no início de 2016 Leonardo Boff, referência internacional da Teologia da Libertação, circulou um texto intitulado "Os equívocos do PT e o sonho de Lula", no qual alude ao governo Morales como um contraponto à trajetória do PT sob Lula:

Na Bolívia, Evo Morales Ayma buscou apoio na vasta rede de movimentos sociais, de onde ele veio como forte líder. Conseguiu, lutando contra os partidos. Depois de anos, construiu uma base de sustentação popular, de indígenas, de mulheres e de jovens a ponto de dar um rumo social ao Estado e lograr que mais da metade do Senado seja hoje composta por mulheres. Agora os principais partidos o apoiam e a Bolívia goza do maior crescimento econômico do Continente (BOFF, 2016).

Esta imagem é difundida pelo próprio presidente Morales, quem anunciou que governaria segundo o princípio zapatista de "mandar obedecendo". A difusão internacional desta leitura também é atestada pela escolha do país para sediar o segundo encontro mundial do Papa Francisco com movimentos populares, em julho de 2015.

A noção de que se trata de um "governo dos movimentos sociais", como diversas outras, encontrou seu principal ideólogo no vice-presidente Álvaro García Linera, um respeitado intelectual com militância prévia no katarismo, corrente política que recuperou o legado das lutas indígenas nos anos 1970. García Lineira cunhou o termo "Capitalismo Andino-Amazônico" para descrever as possibilidades e os limites do governo empossado em 2006, mais recentemente referidas como socialismo comunitario (GARCÍA LINERA, 2015). Subjacente a estes conceitos está a proposição de que o fortalecimento de processos comunitários em um país com as características econômicas e culturais da Bolívia é o caminho para superar o capitalismo no longo prazo. O vice-presidente refere-se 
aos entraves que este processo enfrenta na atualidade, principalmente no campo popular, como as tensões criativas da nuestra revolución, dentre as quais salienta "a contradição criativa entre a necessidade e vontade de industrialização das matérias-primas e a necessidade imprescindível do Bem Viver" (GARCÍA LINERA: 2011, 62, tradução do autor) ${ }^{3}$.

O objetivo deste texto é evidenciar as contradições entre a retórica que caracteriza o proceso de cambio emanada da vice-presidência e as políticas implementadas pelo governo do Movimiento al Socialismo (MAS). Um dos resultados desta cisão é que diversas das principais lideranças indígenas e ambientais do país, bem como numerosos intelectuais críticos e assessorias dos movimentos sociais, engrossaram o voto que derrotou Morales, quando o governo submeteu a referendo o pleito por um quarto mandato em fevereiro de 2016.

Para entender o ponto de vista crítico, delinearemos a evolução do governo entre as disputas para aprovar uma nova constituição, a afirmação do MAS no poder nas eleições de 2009, e a reivindicação de um quarto mandato para Evo Morales em 2016. Minha hipótese é que, ao contrário de uma "contradição criativa", observa-se um distanciamento em relação a um horizonte de mudança social, em prol de um projeto de poder. Ao questionar o caráter popular do governo Morales, este texto problematiza indiretamente a natureza das relações entre esta gestão e os governos petistas no Brasil, sugerindo que as afinidades entre estes governos estiveram referidas antes a projetos de poder com características próprias, do que por um horizonte regional de transformação estrutural. Assim, ao tomar a dinâmica de luta de classes que caracteriza o governo Morales como ponto de partida para compreender a natureza das relações que estabeleceu com outros governos da região, este texto pretende contribuir para uma abordagem marxista das relações internacionais na América do Sul.

Do neoliberalismo à rebelião

A trajetória boliviana a partir da redemocratização em 1982 se assemelha à de diversos países sul-americanos no período, embora com uma intensidade singular. Após uma efêmera tentativa de enfrentar os problemas legados pela ditadura por um governo de centro-esquerda, implementou-se o projeto neoliberal no país. A partir de então, sucederam-se governantes referidos a distintos matizes da política pós-revolucionária (1952), entre o caudilho do MNR (partido identificado com a revolução) e um ex-ditador. Observou-se a corrosão do tecido socioeconômico nos marcos de um debilitamento das organizações de classe convencionais, o que acentuou a vulnerabilidade do campo popular. Enquanto isso, maturavam novos movimentos sociais.

Este processo desgastou os partidos identificados com a política convencional, incapazes de propor uma alternativa às receitas dos organismos multilaterais, que propõem enfrentar os problemas do neoliberalismo com mais neoliberalismo. Esta espiral de degradação só foi freada por um contundente ascenso de novos movimentos sociais, abrindo outro capítulo na história do país.
3. la contradicción creativa entre la necesidad y voluntad de industrialización de las materias primas, y la necesidad imprescindible del Vivir Bien. 
4. poco estructurados, múltiples en su composición (vecinos, gremiales, cocaleros, maestros, campesinos, indígenas) y en sus demandas, pero todos parecidos por su alta intensidad y emotividad expresivas de las fracturas históricas del país
No plano político, a degringolada atingiu seu ponto mais baixo com a eleição do ditador Hugo Banzer em 1997. Seu mandato foi marcado pela adesão à política estadunidense de erradicação da coca, onde presidentes anteriores procuraram contemporizar. A escalada do conflito com os cocaleros projetou nacionalmente o movimento liderado por Evo Morales, que associava a folha da coca a práticas ancestrais e ao nacionalismo boliviano, diante da evidente ingerência estrangeira no país.

$\mathrm{O}$ ascenso do movimento de massas teve como referência inicial a Guerra da Água, que eclodiu em Cochabamba em 2000. A semente do confronto foi o compromisso assumido pelo Banco Mundial em 1997 de perdoar U\$600 milhões da dívida do país se o sistema de águas de Cochabamba fosse privatizado, o que foi realizado em 1999. Assim como ocorreria no altiplano, onde eclodiu um conflito similar, a ideia de pagar pelo uso da água feria os usos y costumbres associados ao modo de vida comunitário enraizado entre os camponeses.

Em ambos casos, a repressão estatal provocou uma escalada do conflito e o campo popular se radicalizou. Em Cochabamba, assembleias populares (cabildos) reuniram mais de 50 mil pessoas rejeitando o controle multinacional sobre os recursos naturais, e ventilando a proposta de uma constituinte. $\mathrm{O}$ mesmo ocorreu em Acachi, onde ressurgia o radicalismo aymara sob a liderança de Felipe Quispe. O governo foi forçado a retroceder (CRABTREE, 2006; HYLTON; THOMSON, 2007; DANGL, 2011; WEBBER, 2013).

Os novos protagonistas das lutas sociais na Bolívia foram descritos como

pouco estruturados, múltiplos em sua composição (barriais, gremiais, cocaleros, professores, camponeses, indígenas) e nas suas demandas, mas todos parecidos por sua alta intensidade e emotividade, expressivas das fraturas históricas do país (LAZARTE, 2015, p. 5, tradução do autor). ${ }^{4}$

Praticavam formas radicais de ação direta, substituindo a tradicional greve, uma forma de luta que freia a produção de mercadorias, pelo bloqueio, que impede a sua circulação. Também cultivavam modalidades de democracia direta, como os multitudinários cabildos abertos, o que encorajou frações do movimento a radicalizar a crítica ao Estado nos anos seguintes.

Um passo importante nesta direção foi esboçado em 2002, quando uma marcha por direitos políticos difundiu a proposta de uma constituinte no imaginário popular. Esta manifestação contrariava os interesses de Morales, então focado nas eleições que ocorreriam em junho daquele ano. Sanchez de Lozada, um ex-ministro associado ao neoliberalismo venceu o pleito, mas com pequena margem em relação ao candidato do MAS (22,5\% versus $20,9 \%)$. A campanha de Evo recebeu um empurrão do embaixador estadunidense, quem declarou que a ajuda econômica deste país cessaria se o líder cocalero fosse eleito (STEFANONI; ALTO, 2014, p. 56).

A Bolívia que Sánchez de Lozada assumiu em 2002 era diferente daquele que encontrou como ministro em 1985. Na primeira ocasião, o então ministro implementou o decreto 21.060, desenhado com assessoria de Jeffrey Sachs, visto como principal marco da inflexão neoliberal. Como em outros casos, houve êxito no controle inflacionário, mas às custas de uma 
notável deterioração do tecido social do país. Um dos países com maior presença do Estado na economia nos anos 1980, um legado da revolução de 1952, era agora uma das economias mais abertas da região. A força de trabalho na informalidade alcançava $68 \%$ e o desemprego triplicara desde 1990 . A Bolívia era o país mais desigual da região, depois do Brasil. A pobreza histórica não diminuíra: $41,3 \%$ da população vivia em extrema pobreza, e os índices de mortalidade infantil e expectativa de vida só superavam ao Haiti. A economia enfrentava crescimento baixo ou negativo pelo quinto ano consecutivo além de um alto déficit do balanço de pagamentos, enquanto dados do Ministério do Trabalho revelavam um aumento significativo das greves e dos protestos sociais (WEBBER, 2013).

A decisão do presidente de implementar um imposto de $12,5 \%$ em todos os salários acima de U\$110, requerido pelo FMI, detonou uma nova onda de protestos em fevereiro de 2003. Policiais de baixo escalão entraram em greve e a brutal repressão do exército desencadeou revoltas populares de distintos setores, que se espalharam a outras partes do país, obrigando o governo a recuar.

Poucos meses depois, divulgou-se um plano de exportar gás boliviano para a Califórnia por portos chilenos, que vinha sendo negociado sigilosamente pelo presidente desde o seu mandato anterior. Esta proposta feria a sensibilidade nacional popular, porque ressoava à histórica exploração estrangeira dos recursos naturais do país, além da delicada relação com o Chile desde a perda da saída para o mar. Eclodia a "guerra do gás".

Nos meses seguintes, numerosas demandas convergiram em torno desta bandeira nacionalista, engendrando uma extraordinária sequência de lutas sociais. O epicentro da revolta foi o município de El Alto, na periferia de La Paz, ocupado e controlado pela população organizada. Novamente, a repressão impiedosa do estado, que resultou na morte de dezenas de pessoas, elevou o nível dos protestos. Os enfrentamentos atingiram proporções épicas, como na noite em que milhares carregaram e arremessaram vagões de trem fechando a ponte que conecta La Paz a El Alto, impedindo até mesmo a passagem de tanques.

No plano político, as demandas se condensaram no que ficou conhecido como "agenda de outubro", propondo fundamentalmente: a industrialização do gás em lugar da sua exportação pelo Chile; não ao Tratado de Livre-Comércio; anulação da lei de "proteção e segurança ao cidadão", que legitimava a repressão; e a renúncia do presidente. O último ponto foi alcançado com a intensificação dos protestos neste mês, que reuniram mais de 300 mil pessoas em La Paz.

O governo foi assumido pelo vice-presidente Carlos Mesa (2003-5), um historiador e comunicador televisivo, filho de prestigiados intelectuais, que aparecia como uma figura ponderada em meio à crise. Foi um polêmico arranjo endossado pelo MAS, que em todos os momentos defendeu uma saída constitucional para a situação. Retrospectivamente, é evidente que o partido calculava um triunfo eleitoral no próximo pleito e tinha interesse em aparecer como um fiador da ordem possível.

A breve presidência de Mesa testemunhou um aguçamento das contradições sociais. O retorno do protesto popular diante da nacionali- 
zação frustrada polarizava com o recrudescimento da reivindicação autonomista da Media Luna, região que concentra os hidrocarbonetos e o agronegócio. Particularmente em Santa Cruz de la Sierra é nutrido um sentimento regionalista ancorado em uma ideologia racista, contrapondo a população das terras baixas (os cambas) aos indígenas do altiplano (os kollas) (SORUCO, 2008). Portanto, uma clivagem regional se mesclava às tensões étnicas e de classe, explicitando na crise as contradições da própria formação do país.

No plano popular, o ascenso das mobilizações foi uma resposta à recusa do governo em considerar a nacionalização dos hidrocarbonetos. Com o apoio do MAS, Mesa articulou um complexo plebiscito com cinco perguntas, mas que elidia a questão fundamental: a expropriação das multinacionais pelo Estado. Na medida em que as mobilizações se intensificavam em ambos polos, Mesa se alinhou com Santa Cruz e a "agenda de janeiro" em defesa da autonomia dos negócios, o que forçou um reticente MAS a distanciar-se de um governo de quem era aliado informal. As manifestações tornaram a adquirir proporções multitudinárias, reunindo meio milhão de pessoas em La Paz. Mesa não convocou os militares para reprimir, mas acossado no congresso e nas ruas, renunciou.

A despeito de indícios de que a mobilização popular crescia, se radicalizava e fortalecia sua autonomia em relação a 2003, novamente Morales intercedeu no sentido de limitar os desdobramentos do processo ao plano político. A expectativa de um triunfo eleitoral o levou a favorecer que a efervescência das ruas se canalizasse para uma saída institucional. Foi assim que, em dezembro de 2005, tornou-se um dos raros presidentes da Bolívia eleito com a maioria dos votos (54\%). Iniciava-se o chamado proceso de cambio.

O Proceso de cambio entre a constituinte e o TIPNIS

O governo do MAS enfrentou em seus primeiros anos um desafio crucial. Em consonância com a reivindicação popular, Morales seguiu o caminho trilhado por Chávez e convocou uma assembleia constituinte. De antemão, a decisão de que a representação congressual seria canalizada por partidos, interditando a participação por movimentos ou por nações indígenas, foi interpretada como um revés para o campo popular, praticamente obrigando a filiação ao MAS. Porém, a eleição concedeu a esta agremiação apenas a maioria simples no congresso (54\%), aquém dos $2 / 3$ necessários para avançar sem compor com outras forças. As esperanças de mudança que confluíram para o plenário se defrontaram com uma oposição decidida a impedir a nova constituição, a pretexto de uma demanda por descentralização e autonomia articulada a partir de Santa Cruz. O substrato econômico do separatismo crucenho é a pujança do agronegócio e a concentração de hidrocarbonetos na "Meia Lua" boliviana, o que a converteu nos decênios recentes na região mais rica do país.

A intransigência oposicionista deflagrou um clima de permanente tensão, entre a ameaça separatista e a iminência de guerra civil, uma vez que a base masista do altiplano cogitava cercar seus inimigos. Foi neste contexto que o embaixador estadunidense Philip Goldberg foi expulso do 
país, acusado de financiar os autonomistas e em seguida, a própria Drug Enforcement Administration (DEA). O desenlace do impasse exigiu prolongadas negociações nas quais o governo cedeu às demandas da oposição que, não obstante, reescreveu 130 artigos do texto acordado. A nova constituição só foi referendada em 2009, o que diante das circunstâncias, foi interpretado como uma vitória política do MAS.

De fato, nas eleições gerais que se seguiram, Evo foi reeleito com $64 \%$ dos votos, e o MAS conquistou maioria de $2 / 3$ no congresso e no senado. A oposição constitucional articulada em torno do PODEMOS se dissolveu, em um cenário em que a força dos partidos tradicionais foi esvaziada. Os anos seguintes confirmaram este debilitamento dos partidos que tradicionalmente articulavam o poder conservador. Uma das consequências imprevistas do processo foi uma aproximação entre setores associados aos negócios e o partido do governo, como veremos. Por outro lado, o MAS contava neste momento com uma sólida base popular em torno do Pacto de Unidad, selado em 2004 entre as principais organizações do país: CSTUCB, Bartolina Sisa, CONAMAQ, cocaleros e os indígenas de terras baixas reunidos na Confederación de Pueblos Indigenas de Bolivia (CIDOB). A situação que García Linera descreveu como empate catastrofico, referindo-se ao período inaugurado em 2003, se desempatava. E dava em goleada.

Ao contrário do que se poderia esperar, nos anos seguintes houve seguidas defecções no campo popular, e importantes adesões da oligarquia. A primeira marcha contra Morales realizou-se em 2010, reivindicando a autonomia territorial. Esta era uma demanda central para os povos indígenas, associada à plurinacionalidade consagrada no novo nome do país: Estado Plurinacional de Bolivia. Em contraste com políticas multiculturalistas implementadas na primeira presidência de Sánchez de Lozada, o controle territorial implica em soberania política, o que por sua vez, sinaliza para uma justiça própria e relações econômicas distintas. No entanto, a regulação da lei impõe um conjunto de travas para realizar este direito constitucional resultando em que, na prática, o que há são distritos e municípios indígenas como parte da estrutura do Estado que pretendeu-se modificar. Schavelzon sintetiza o paradoxo: "a autonomia nasceu como uma consigna para debilitar o Estado. Agora, o Estado se indianizou e a autonomia perde a força que teve antes" (SCHAVELZON, 2015, p. 53, tradução do autor) ${ }^{5}$.

Um segundo antagonismo entre o governo e sua base foram os protestos em resposta ao decreto promulgado no Natal de 2010, instituindo um imposto que elevaria em mais de $70 \%$ o preço final dos combustíveis. Divulgado como uma medida necessária para frear a sangria dos cofres públicos causada pelo subsídio aos combustíveis, uma minuciosa pesquisa revelou que a iniciativa explicitava os limites da nacionalização dos hidrocarbonetos.

Anunciada no primeiro de maio de 2006 em meio a intensa emoção, a nacionalização se traduziu, no frigir dos ovos, em um aprofundamento da reforma tributária iniciada em 2005 sob Mesa, quando os impostos subiram de $18 \%$ para $50 \%$ no setor. A revisão dos contratos entre as multinacionais e o Estado elevou outra vez os tributos, que totalizaram $62,5 \%$
5. la autonomía nació como una consigna para debilitar el Estado. Ahora el Estado se ha indianizado y la autonomía pierde su fuerza que tuvo antes. 
(ARCE; GÓMEZ, 2013, 78), ao mesmo tempo em que deu nova vida a YPFB por meio da compra, a preços altos, de metade mais uma das ações de cinco empresas que no passado, foram estatais. Porém, o Estado não comanda o setor, já que as multinacionais mantiveram controle sobre as reservas e a extração, inclusive dos chamados megacampos, dos quais depende a produção de gás e petróleo do país. Apesar da taxa de lucro das empresas ter diminuído, a massa de lucro aumentou, uma vez que o valor da produção quase triplicou entre 2004 e 2010. Em 2010 as multinacionais controlavam mais de $80 \%$ da produção, percentual que tem crescido, com destaque para a participação da Petrobras que se elevou de 56,7\% em 2005 para 63,7\% em 2010 (ARZE; ESPADA; GUZMÁN; POVEDA, 2011; RODRÍGUEZ CÁCERES; GANDARILLAS, s/d).

Distante de uma expropriação ou do monopólio estatal do setor, a medida respeitou integralmente os direitos das empresas estrangeiras, sob a lógica de que o investimento externo é imprescindível para desenvolver o setor. No entanto, o volume da produção de hidrocarbonetos não tem crescido, em um país onde o investimento privado tem sido inferior a $10 \%$ do PIB (MOLINA, 2015, p. 27). O aumento dos lucros e dos impostos arrecadados corresponde à elevação dos preços internacionais destas matérias-primas, em uma economia cada vez mais dependente de hidrocarbonetos: entre $2001-2005$, respondiam por $47 \%$ do total das exportações, percentual elevado para $69 \%$ no último quinquenio (REQUENA, 2015, p. 21). Por outro lado, a importação de gasolina subiu de 3\% para 9\% dos totais no período. Apesar da crescente receita fiscal, o governo central tem apresentado déficits recorrentes, motivados principalmente pelo aumento dos gastos correntes relacionados ao incremento da burocracia estatal, cujo pessoal quintuplicou. Aliás, são os resultados das empresas estatais que embasam os propalados superávits fiscais (ARZE; ESPADA; GUZMÁN; POVEDA, 2011, p. 24).

Enfrentando um cenário de estancamento da produção de hidrocarbonetos, o estado boliviano se viu constrangido a gerar novos impostos, ou recorrer ao endividamento externo. Impotente diante das multinacionais, o principal móvel do novo imposto em 2010 foi constituir um fundo que viabilizasse um adicional de U\$32 por barril, elevando os lucros das empresas em cerca de $400 \%$ com o intuito de estimulá-las a aumentar a produção. Os protestos conhecidos como gasolinazo obrigaram o governo a reverter a medida. Porém, em abril de 2012 decretou-se um incentivo de U\$ 30 por barril, o que constitui uma subvenção duas vezes maior do que a renda obtida por meio do Imposto Direto sobre Hidrocarbonetos (IDH) e dos royalties obtidos sobre o preço vigente de U\$ 27,11 (ARCE; GÓMEZ, 2013, p. 84).

A determinação do governo em intensificar a exportação primária, entre hidrocarbonetos, minérios e o agronegócio, também está relacionada à pressão fiscal. Uma expressão deste movimento é o progressivo rebaixamento dos requisitos socioambientais para a expansão destas atividades no país, em contradição com preceitos constitucionais e a imagem de protetor da mãe-terra. O conflito em torno do Territorio Indigena y Parque Nacional Isiboro Sécure (TIPNIS) que aflorou em 2011 condensou estas tensões, e é considerado um ponto de inflexão na relação do governo os movimentos indígenas. 
Como seu próprio nome descreve, o TIPNIS é simultaneamente um território indígena e uma área de proteção ambiental desde os anos 1960, ambas figuras jurídicas que o resguardam do progresso. Porém, o governo Morales iniciou a construção de uma rodovia atravessando o parque, em uma obra adjudicada à empreiteira brasileira OAS. De imediato, o projeto foi associado à controvertida Iniciativa para a Integração da Infraestrutura Regional Sul-Americana (IIRSA), uma ampla carteira de projetos infraestruturais concebida pelo BID e impulsionada pelas gestões petistas (VILLEGAS, 2015). Mais além do negócio empreiteiro, salientam-se como motivações subjacentes à obra a prospecção de petróleo e a expansão dos colonizadores cocaleros. Embora a população indígena do TIPNIS seja relativamente pequena, estimada em 2 mil famílias, avaliou-se que a realização da obra colocaria em risco todos os territórios em situação similar (PAZ, 2015). Por outro lado, a retórica governamental é que não se pode arriscar o futuro do país por uns poucos.

Sob a liderança da CIDOB e dos indígenas de terras baixas, organizaram-se diversas marchas de protesto, em uma tradição que remonta à mobilização original em 1990. Dentre estas a oitava, realizada em 2011, teve repercussão internacional. Nesta ocasião, o governo reprimiu brutalmente os manifestantes em Chaparina. Adultos foram sequestrados, famílias dispersadas na selva, crianças desapareceram por dias e houve ao menos três mortos, dentre os quais duas crianças. Há registros de três grávidas que perderam os filhos por espancamento. A repressão gerou solidariedade popular, e a queima de pneus impediu o embarque das lideranças aprisionadas em um aeroporto nas imediações. Ao final do percurso, os manifestantes foram recebidos por uma multidão em La Paz, enquanto CIDOB e CONAMAQ se retiravam do Pacto de Unidad. Nesta mesma conjuntura um nutrido grupo de intelectuais, alguns dos quais ocuparam altos cargos no governo, circularam um Manifiesto por la recuperación del Proceso de Cambio para el pueblo y con el pueblo. A base de apoio de Morales se fraturava (FUNDACIÓN TIERRA, 2012; CUSICANQUI, 2015, pp. 48-49; ÁVILA, 2015; CHÁVEZ, 2015; PAZ, 2015).

A reação do governo aos setores populares que gravitaram para a oposição tem sido implacável. CIDOB e CONAMAQ foram divididas e suas sedes ocupadas por setores aliados. O governo criou uma central alternativa (Consejo Indigena del Sur, Conisur) que fez uma contramarcha. Lideranças são difamadas e criminalizadas. Organizações que apoiam o governo recebem dinheiro enquanto as opositoras, são sufocadas. A sede da Cordinadora Obrera Departamental (COD) em Santa Cruz, onde está em construção um hotel nos fundos do terreno, contrasta com a apertada garagem na periferia da cidade em que se reúne o setor autônomo da CIDOB. Em Cochabamba, a ampliação e reforma da sede das Seis Federações do Trópico de Cochabamba foi entregue no final de 2015, em festa que teve bolo com a cara do presidente.

A perseguição se estende àqueles que apoiam estes grupos dissidentes: uma Organização Não Governamental (ONG) dinamarquesa que financiava a organização de grupos originários foi expulsa do país, a Ibis, e diversas outras enfrentam problemas, inclusive as nacionais. Em 2016, três reputados centros de investigação e assessoria a movimentos enfren- 
6. defender los intereses de las fuerzas conservadoras de derecha, socavando su propio proceso revolucionário; reproducen mecanismos de coptación clientelar y subordinación ideológica hacia las agencias de financiamiento, la mayor parte de ellas europeas y norteamericanas; intelectuales organicos de la restauración de la colonialidad. tavam uma campanha difamatória do governo sob a liderança de García Linera, ameaçando suas atividades: CEDLA, Fundación Tierra e CEDIB, além da Fundación Milenio, alinhada ao neoliberalismo.

$\mathrm{O}$ vice-presidente difama os opositores com notável virulência. Por exemplo, no folheto em que defende a estrada do Tipnis, acusa os movimentos que marcharam de "defender os interesses das forças conservadoras de direita, socavando seu próprio processo revolucionário"; diz que as ONG's "reproduzem mecanismos de cooptação clientelar e subordinação ideológica às agências de financiamento, a maior parte delas europeias e norte-americanas"; enquanto os críticos à estrada são "intelectuais orgânicos da restauração da colonialidade" (GARCÍA LINERA, 2012, p. 14, p. 26, p. 84, tradução do autor) ${ }^{6}$. O grupo de notáveis ex-dirigentes do governo que assinou o manifesto pela recuperación del Proceso de Cambio foi taxado como "ressentidos políticos" na resposta do vice-presidente, o panfleto intitulado El 'oenegismo', enfermedad infantil del derechismo (GARCÍA LINERA, 2013a). O simplismo das acusações é análogo à lógica da Guerra Fria, em que todo opositor é inimigo da revolução: um direitista a serviço do imperialismo.

A base social

Portanto, a autoreferência deste como um "governo dos movimentos sociais" precisa ser no mínimo, qualificada. Apoiam incondicionalmente Morales sua base de origem, os cocaleros. Ao contrário do que se possa imaginar, não se trata de uma organização indígena do ponto de vista socioeconômico, mas camponesa. Porque em um país como a Bolívia, em que a imensa maioria da população tem fenótipo indígena, é necessário diferenciar entre os indígenas urbanos, que podem ser ricos como a burguesia comercial aymara, ou pobres como a maioria; indígenas camponeses, que concebem a terra como uma mercadoria a ser explorada, como é o caso dos cocaleros e do próprio Morales; e os indígenas comunitários, cuja forma de vida está vinculada a uma relação orgânica com o território (ÁVILA, 2015; VADILLO, 2015; RIBERA ARISMENDI, 2015). Daí as tensões entre os indígenas de terras baixas e os cocaleros, cuja expansão colonizadora os converteu em "ponta de lança do projeto anti-comunitário" (ÁVILA, 2015). Outra clivagem a ser tomada em conta é que a maioria dos indígenas camponeses e urbanos é de extração quechua ou aymará, enquanto dezenas de outros povos de pouca relevância demográfica, não o são. É nesta perspectiva que o dirigente da CIDOB, Adolfo Chávez, se queixa que no governo do MAS, a "descolonização seria nos fazer quechuas ou aymaras” (CHÁVEZ, 2015).

A despeito da simpatia internacional que a descriminalização da folha de coca mobiliza, identificada com direitos indígenas (com os quais na realidade, antagoniza na Bolívia), esta é uma atividade econômica nebulosa. Os bolivianos dizem que a coca para consumo interno é a folha macia produzida nos Yungas, nas cercanias de La Paz. Daí a suspeita generalizada de que os cocaleros do Chapare, base original de Morales, estão envolvidos com o narcotráfico, auferindo rendimentos por hectare muito superiores à soja. Há indícios de que o país atualmen- 
te não somente planta a folha, mas processa cocaína peruana, metade da qual é vendida para o Brasil, segundo mercado mundial. Os produtores da região são organizados e incondicionalmente fiéis ao hermano Evo, a quem consideram um dever defender. Com certa ironia, há quem comente que o Chapare é o único território realmente autônomo no país (VADILLO, 2015). Há poucas investigações a respeito, inclusive porque pesquisadores relatam medo em se envolver com o tema. Mas existe a percepção de que esta atividade não tem um papel secundário no desempenho econômico do país, gerando recursos que não são contabilizados no PIB, mas que ingressam na economia por meio da construção civil e da importação.

Não menos importante, há diversos escândalos envolvendo funcionários de alto escalão do governo com o narcotráfico. Em 2011 a Drug Enforcement Administration (DEA), que foi expulsa da Bolívia por Morales, prendeu no Panamá a Rene Sanabria, diretor da Fuerza Especial de Lucha Contra el Narcotráfico (Felcn). Em outras palavras, o tsar antidrogas do país. Extraditado e condenado a quinze anos de prisão, o general divulgou uma carta quando seu filho foi preso na Bolívia por enriquecimento ilícito, acusando o governo de acobertar diversos funcionários envolvidos com a corrupção e o narcotráfico. Neste diapasão, em 2013 foi preso o chefe da Dirección General de la Hoja de Coca e Industrialización (Digcoin), Luis Cutipa, acusado de revender a cocaína que apreendia. No entanto, foi solto após duas semanas, em uma situação que expõe outra vulnerabilidade democrática do governo: a dependência da justiça. Esta conjunção entre a expansão cocalera no Tipnis, escorada pelo Estado; escândalos envolvendo autoridades do mais alto nível; numerosos indícios de lavagem de dinheiro, como prédios que se multiplicam em Cochabamba pagos em dinheiro, levam o reputado intelectual Alejandro Almaráz, Viceministro de Terras do governo até 2010, a descrevê-lo sem peias como um "governo narcotraficante" (ALMARÁZ, 2015).

A base camponesa do governo, que tem nos cocaleros um aliado incondicional, é reforçada por movimentos que integram o Pacto de Unidad, além das facções fiéis das organizações indígenas fraturadas. Muitas destas acessaram o chamado Fondo Indígena, constituído a partir de uma fração das receitas de hidrocarbonetos para financiar projetos de desenvolvimento. Porém o fundo acabou se convertendo em uma fonte de denúncias de corrupção afetando os movimentos e o governo, até ser extinto pelo presidente em agosto de 2015 . No final daquele ano, um relatório do fiscal general do país indicava 49 obras fantasma, envolvendo o desvio de U\$ 6,8 milhões, resultando no indiciamento de 205 pessoas e na detenção de outras 24 figuras, incluindo a ex-ministra de Desarrollo Rural $y$ Tierras e dirigente da organização camponesa Bartolina Sisa, Julia Ramos, dois senadores, e outras lideranças sociais governistas, como a chefe da CIDOB governista (BBC, 2015).

Sindicatos mineiros também compõem a base do governo, embora o setor seja apenas uma sombra do que foi no passado (CAMPOS; TOSITO; ROMERO, 2015). A Central Obrera Boliviana (COB) chegou a romper com o governo, mas reatou laços em 2013, depois de "derrotada a utra-esquerda no seio dos sindicatos mineiros” (RADA VÉLEZ, 2015, p. 4, 
7. derrotada la utraizquierda en el seno de los sindicatos mineros. tradução do autor) $)^{7}$. Na realidade, as cooperativas mineiras são pequenos e médios capitalistas conhecidos pela superexploração do trabalho, enquanto a grande mineração é comandada pelo capital internacional. Também neste setor, em que apenas duas minas são operadas pelo Estado, não houve qualquer intenção de afetar as empresas transnacionais. O governo limitou-se a instituir um imposto de $12,5 \%$ sobre os lucros extraordinários das empresas e embora a arrecadação dobrasse no decênio passado em função dos altos preços, o poder político das cooperativas mantém a tributação muito abaixo dos hidrocarbonetos (Escobar: 2015). No período, a contribuição fiscal da mineração esteve em torno de um sétimo dos hidrocarbonetos, embora sua participação no PIB seja 1,7 vezes maior (ARZE; GÓMEZ, 2013, p. 105). A importância destes setores para os ingressos tributários do país tem alienado a preocupação socioambiental. Em 2014, o governo decretou a Ley de Minería y Metalurgia, autorizando a exploração em áreas protegidas e glaciares, fontes críticas de provisão de água no altiplano. Na sequência, o decreto 2366 de maio de 2015 autorizou a exploração de hidrocarbonetos em 8 áreas protegidas. Assim, não se vê motivo para oposição destes setores ao governo.

Outro grupo social que apoia Morales é a chamada "burguesia aymara", migrantes de origem rural que ascenderam por meio do comércio de importação, lícito ou não. Muitos ostentam sua cultura e seu poder econômico, simbolizados nos edifícios de arquitetura peculiar que pululam em El Alto e são conhecidos como cholets. O paradoxo é que o sentido geral da política do governo, que se apoia neste orgulho aymara ao mesmo tempo em que reprime o plurinacionalismo, como se observa no episódio do TIPNIS, tem incidido negativamente na autoidentificação do indígena, que atingia $62 \%$ no censo de 2001 e caiu para $40 \%$ em 2011.

Trata-se de uma burguesia comercial porque, a despeito do discurso oficial, a industrialização não tem sido uma prioridade do governo. Em 2012, somente três das nove plantas manufatureiras estatais projetadas em 2007 estavam em operação. E embora a constituição fale em uma economia plural, prevendo quatro setores (comunitária, estatal, privada e social-cooperativa), a ênfase na exportação primária inibe a diversificação produtiva. Do ponto de vista das relações de trabalho, o próprio García Linera reconhece que, ao estimular a economia comunitária, o objetivo não é competir com o setor privado, mas ajudar os produtores rurais, em uma modalidade de política social (GARCÍA LINERA, 2013b, 46).

O governo também tem importado produtos diversos, principalmente alimentares, como parte de uma política social que visa simultaneamente conter a inflação. Ancorado em uma moeda apreciada em relação ao dólar, esta política desestimula a produção local, fazendo com que as oportunidades de lucro gravitem em torno da renda extrativa, seja por meio do setor de serviços ou da importação. É uma economia cada vez mais consumista, e cada vez menos produtiva.

Talvez o maior impacto desta orientação econômica se dê no campo. O valor per capita da importação de alimentos triplicou na última década, passando de 24 para 70 dólares, além de um subsídio calculado em 800 bolivianos por família no preço de açúcar, pão, leite e frango (URIOSTE, 2015, p, 22). A Bolívia importa hoje hortaliças, frutas e até batatas do 
Peru, um patrimônio andino (ESCOBAR, 2015).

Como decorrência, o modo de vida camponês associado a uma relação orgânica com a terra, seja nos marcos de uma cosmovisão andina ou não, mas em contraste com a mentalidade mercantil do monoprodutor rural, está em acelerada decomposição. Calcula-se que 79\% dos alimentos consumidos no campo sejam agora comprados da agroindústria. Em paralelo, prosperam atividades mais rentáveis orientadas à exportação, como é o caso da quinua. Muitos deixam de ser agricultores e se engajam no pujante setor de transportes nas cidades, vendem sua força de trabalho na construção civil ou emigram (URIOSTE, 2015, p. 22).

No início, pareceu que seria diferente. Encampando o discurso de uma segunda Revolución Agraria, o primeiro governo do MAS (2006-2009) acelerou o processo de saneamento dos títulos fundiários iniciado em 1996, regularizando cerca de 20 milhões de hectares entre 2005 e 2010, embora só houve efetiva mudança de propriedade em cerca de 4 milhões de hectares (Almaraz: 2015, 23; Arce; Gómez: 2013, 92). Porém, a maioria das terras distribuídas a TCOs pertenciam ao próprio governo (tierras fiscales), onde apenas de $821 \mathrm{mil} \mathrm{h} / \mathrm{a}$ se redistribuíram por não cumprirem sua função econômica até 2011 (ORMACHEA; RAMÍREZ, 2013, p. 82). Esse processo foi freado em seu ritmo e sentido a partir de então, saneando-se principalmente propriedades da oligarquia rural.

No segundo governo do MAS intensificou-se a aproximação entre o governo e o agronegócio crucenho, notável em alguns movimentos. Em 2011, a Ley de la Revolución Productiva liberou o cultivo transgênico, que em 2008 fora proibido. A seguir, o governo acatou duas demandas explícitas do setor. Embora o país desmate cerca de $200 \mathrm{mil}$ ha por ano, situando-se entre as maiores contribuições per capita à emissão de $\mathrm{CO} 2$ do mundo (REQUENA, 2015, p. 21), foi promulgada em janeiro de 2013 a Ley de Apoyo a la Producción de Alimentos y Restitución de Bosques. Esta lei foi apelidada como perdonazo, pois anistiou mais de 2 milhões de hectares de terras desmatadas que deveriam ser revertidas ao Estado. Simultaneamente, o governo acordou uma pausa de cinco anos na verificação do cumprimento da função social da terra prevista na constituição, o que novamente, é uma trava explícita à desapropriação fundiária. Mas o indício mais claro de compromisso perene com a oligarquia crucenha foi o anúncio em 2014 da intenção de ampliar a fronteira agrária em 10 milhões de hectares até 2025, a pretexto de assegurar a soberania alimentar. Pouco depois, a Asociación Nacional de Productores de Oleaginosas y Trigo (ANA$\mathrm{PO}$ ), organização do agronegócio oriental, assumiu a responsabilidade de delinear uma estratégia com este propósito, materializando um dos objetivos da Agenda Patriótica 2025 lançada por Morales (CONDORI, 2015) - que como se nota, tem planos de longo prazo para o país. Em resumo, "o MAS, de maneira natural e vertiginosa, vai se transformando no partido que represesnta os interesses gerais do poder empresarial-fazendeiro" (ORMACHEA; RAMÍREZ, 2013, p. 98, tradução do autor) ${ }^{8}$.

Diante desta realidade, é possível argumentar que a principal causa do esvaziamento da oposição e do apaziguamento da agitação autonomista, é que o governo lhes roubou a agenda política e a base de apoio. Partidários do finado Hugo Banzer associaram-se ao MAS, enquanto os
8. el MAS, de manera natural y vertiginosa, va transformándose en el partido que representa los intereses generales del 'poder empresarial-hacendal. 
9. a los invitados se recibe en la sala

10. Tras una ola de cambios de propietarios, los nuevos dueños archivaron el asedio previo (ao MAS). ATB, La Razón,

PAT y el Extra mudaron de dueño y accionistas. Unitel y la red UNO suavizaron radicalmente su línea editorial. En 2013, el presidente le comentaba al diario El Deber que ya sólo un 10\% de los medios se enfrentaba a su administración. cívicos de Santa Cruz colocaram candidatos no partido. Esta situação levou o histórico líder guerrilheiro Osvaldo Peredo, ex-vereador pelo MAS, a comentar constrangido sobre as alianças realizadas pelo partido que "os convidados se recebe na sala"” e não no quarto de dormir (PEREDO, 2015, tradução do autor).

É certo que persiste uma oposição histriônica, vinculada aos grupos e partidos políticos eclipsados pela ascensão do MAS, consolidada desde a promulgação da nova constituição. Esta oposição é motivada antes pelo seu alijamento do poder do que por uma disputa de projeto, que não há. Estes recalcitrantes também se arriscam a enfrentar o longo braço do MAS, que controla órgãos eleitorais, o judiciário, e os meios de comunicação. Há o reconhecimento generalizado de que as últimas eleições regionais foram manipuladas em Beni e Chuquisaca. Para dar um exemplo, em Beni anularam-se 228 candidaturas, todas da oposição. O detonante do processo foi a menção de uma pesquisa por um porta-voz da oposição, quando a lei eleitoral proíbe referir-se a sondagens não oficiais, embora as duas que existam sejam patrocinadas pelo governo. Como decorrência, quitaram a personalidade jurídica do partido (ALMARAZ, 2015).

Ajuizamentos políticos tem se naturalizado, à esquerda e à direita do espectro político. Almaraz cita o caso do filho de um político reacionário de Santa Cruz, que em 2015, estava preso há 7 anos, acusado de tramar um golpe baseado em chamada telefônica de 17 segundos (ALMARAZ, 2015). O objetivo político da prisão seria dobrar o pai, em um país em que a polícia tem liberdade absoluta de atuação. Há quem afirme que há tanto medo agora como no tempo da ditadura (GANDARILLAS, 2015).

No campo da imprensa, ao contrário do que alguns supõem, tampouco circula uma oposição consistente. Um jornalista comenta:

\footnotetext{
Após uma onda de mudança de proprietários, os novos donos arquivaram o assédio prévio (ao MAS). ATB, La Razón, PAT e o Extra mudaram de dono e acionistas. Unitel e a rede UNO suavizaram radicalmente sua linha editorial. Em 2013, o presidente comentava ao diário El Deber que somente uns $10 \%$ dos meios se enfrentavam com a sua administração . (ARCHONDO, 2015, p. 34, tradução do autor $)^{10}$.
}

Há suspeitas de que García Linera cumpriu um papel central na articulação que produziu esta situação. O vice-presidente nega o controle dos meios de comunicação, afirmando que só possui livros. Internamente, muitos associam sua imagem à frente empresarial do governo e à corrupção, que se estenderia a familiares.

A economia política de Morales

Porém, há o reconhecimento de que Morales é o líder político indiscutível do governo. Esta liderança se trasveste cada vez mais em personalismo, em um partido em que não há democracia interna, e em um governo empenhado em não projetar sombras sobre sua estrela maior (ALMARAZ, 2015). Esta pode ser uma explicação para a nomeação de alguns ministros, que parecem atender a critérios superficiais de ressonância publicitária, como por exemplo, a procura de uma indígena com formação em direito para o ministério de Justiça. O verniz ideológico 
deste personalismo, que se expressou na tentativa de conduzir Morales a um quarto mandato, foi antecipado por García Lineira, sob a noção de "evismo, o nacional popular em ação" (GARCÍA LINERA, 2006b).

Mais além da disputa ideológica e política, a orientação macroeconômica do projeto comandado por Morales tem sido aumentar a arrecadação estatal por meio da intensificação da exportação primária, de modo a potencializar o investimento público, o que de fato tem ocorrido. Em contraste com o baixo nível do investimento privado, a inversão pública se multiplicou por quatro nos últimos anos, orientado principalmente à infraestrutura, basicamente rodovias (ESCOBAR, 2015). Projetos produtivos, orientados a diversificação econômica e a industrialização não são priorizados, de modo que o crescimento tem sido impulsionado pela exportação primária, a construção civil, a administração pública e a economia delitiva.

O aumento das receitas fiscais facilitou a difusão de políticas de transferência monetária condicionada visando reduzir a pobreza, como ocorreu em muitos países da região. Na Bolívia, são três bonos fundamentais: o programa Juancito Pinto atinge crianças em idade escolar, que recebem U\$ 30 por ano; o programa Juana Azurduy é voltado para gestantes, intituladas a receber U\$ 7 a cada vez que comparecem a uma consulta médica; e os idosos recebem cerca de 1 U\$/dia pelo programa Renta dignidad, que movimenta mais recursos do que os dois primeiros somados. Trata-se do aperfeiçoamento de uma iniciativa lançada em 1996, sob o impacto de uma reforma previdenciária mais brutal do que a chilena. É difícil avaliar a incidências destes programas para o alívio da pobreza no país, mas os dados indicam que o volume das remessas de expatriados ao país é no mínimo, três vezes maior (ARZE; GÓMEZ, 2013, p. 117).

As estatísticas oficiais indicam uma redução da pobreza, que chegou a cair quase $30 \%$ em um ano (2008) em função de uma alteração na metodologia do Banco Mundial. Isso levou a Bolívia a ser considerada um país de ingresos medios, qualificando-se a empréstimos não concessionados a preços de mercado. Porém, não houve mudanças no mundo do trabalho endossando este ascenso, em um país em que metade da população urbana ainda vive em condição de subsistência (ESCOBAR, 2015).

Considerando que os índices internacionais geralmente se referem à pobreza como uma renda inferior a U\$ $2 /$ dia, e à pobreza extrema como uma renda inferior a U\$ 1/dia, é preciso levar em conta a apreciação cambial, em que a cotação do boliviano se manteve estável apesar da inflação nos últimos anos. Os dados indicam que o aumento dos salários tem sido impotente para responder ao aumento do custo de vida, exceto no setor público. Em 2004, o salário mínimo comprava 99\% de uma cesta básica familiar e em 2010, alcançava $74 \%$, o que revela uma perda de poder aquisitivo. Neste último ano, cerca de dois terços dos trabalhadores ocupados tinha uma remuneração inferior à cesta básica familiar. A fatia da renda correspondente ao trabalho se reduziu de $36 \%$ em 2000 para $25 \%$ dez anos depois, enquanto a parcela do capital subiu de $47 \%$ para $55 \%$, revelando uma economia que cresce superexplorando o trabalho (ARCE; GÓMEZ, 2013, pp. 133-142).

O outro lado da ênfase em programas de transferência de renda condicionada, é que o gasto público social não foi priorizado. O gasto do estado 
11. Expressão utilizada pelo Vice-Presidente García Linera, entre outros, para referir-se ao poder conservador que tem como base a propriedade fundiária no país. em saúde e educação é menor do que o gasto privado. Somente $35 \%$ dos assalariados são cobertos pelo sistema de saúde e $38 \%$ pelo sistema de pensão, o que corresponde a entre 13 a $14 \%$ da população economicamente ativa. A precariedade do sistema de saúde, em um país onde morre uma criança a cada meia hora e uma mulher no parto a cada três dias, contrasta com o altíssimo orçamento de defesa e os benefícios a que acedem os militares como por exemplo, aposentadoria integral em um país em que as pensões são baixíssimas e a contribuição tripartite está abolida (SAUCEDO, 2015). Em suma, o sentido da legislação neoliberal permanece vigente, apesar da derrogação simbólica e parcial do decreto 21.060 em 2011.

Conclusão

Emergindo na crista da mobilização popular mais radical do início do século XXI no subcontinente, a eleição de Evo Morales em 2005 pretendeu devolver a política das ruas para o parlamento. Enquanto alguns anteciparam a frustração de um processo que, em seu momento, ameaçava as estruturas do Estado, prevaleceu o sentimento de que seria possível modificá-lo substantivamente pela via parlamentar. Em outras palavras, a reforma se impôs sobre a revolução.

A inauguração do processo constituinte aguçou as contradições sociais do país, expondo clivagens de classe, étnica e regional. Confrontada com uma agenda emanada do bloco popular, a reação se articulou em torno da Media Luna, ameaçando a própria unidade do país. O desenlace do que García Linera descreveu como "empate catastrófico" implicou em significativas concessões do campo popular, sinalizando o que estava por vir. Mas em 2009, muitos interpretaram a aprovação da nova constituição como uma vitória.

Naquele momento, a posse em Tiwanaku, a defesa da Pachamama, o Estado Plurinacional, a reivindicação ancestral da folha de coca, a nacionalização dos hidrocarbonetos e a ressurreição da YPFB, a expulsão do embaixador estadunidense e da DEA, o alinhamento com Chávez e a ALBA, a súbita projeção internacional do país, o saneamento de terras, a proibição dos transgênicos, os bonos sociais, eram indícios de que estava em andamento um proceso de cambio. E por ele, Morales foi reeleito em 2009 com $64 \%$ dos votos, em um pleito que lhe assegurou maioria parlamentar absoluta.

Paradoxalmente, o desmanche da direita partidária correspondeu a uma guinada do governo nesta direção, intensificando as relações com o poder hacendal-patrimonialista ${ }^{11}$ ao mesmo tempo em que aprofundava o compromisso com a exportação primária. Esta articulação revelou-se incompatível com as expectativas de plurinacionalidade, soberania e defesa do meio ambiente, que afloraram na marcha indígena de 2010, no gasolinazo, e sobretudo no conflito em torno do TIPNIS.

Escorado nas alianças conservadoras que solidificou, o governo enfrentou a dissidência popular, que tem crescido, com intolerância retórica e repressão política.

A partir de então, acumulam-se as desilusões: o plurinacionalismo se trasveste de burguesia aymara, enquanto referências a Tupac Katari 
adornam os cholets e aviões LATAM; a justiça comunitária é criminalizada pela justiça comum; a autonomia territorial só acontece no Chapare; a reivindicação da coca enturva o envolvimento da base social do governo e de autoridades com o narcotráfico; o governo dos "movimentos sociais" corrompe os fiéis, enquanto esmaga os dissidentes; estendeu sua dominação aos órgãos eleitorais, ao poder judiciário e à imprensa; o poder hacendal-patrimonial compõe a base do governo, ao lado do partido do ex-ditador; a soja prospera, o campesinato fenece; a "nacionalização" é impotente para responder às necessidades nacionais mais básicas no setor; a oposição aos Estados Unidos convive com a defesa do capital internacional, e a emulação ao Brasil; o engajamento na ALBA é instrumental, atrás de recursos venezuelanos; o Vivir Bien é massacrado pelo extrativismo.

Neste contexto, o projeto subjacente ao pleito por um quarto mandato para Morales esteve distante de "transitar da revolução democrátia e cultural à revolução econômica e social, em um processo que permita iniciar a construção do socialismo comunitário sob o paradigma do Bem Viver" (RADA VÉLEZ, 2015, p. 4, tradução do autor) ${ }^{12}$. É preciso desmistificar a imagem de um bloco evista "nacional-popular", que enfrenta uma oligarquia racista em aliança com movimentos e ONGs insuflados pelo imperialismo. A análise mostra que, em um processo análogo às gestões petistas no Brasil, o MAS tem instrumentalizado o conhecimento e confiança que tem das organizações sociais para superar obstáculos à exploração dos hidrocarbonetos e do agronegócio, engajando-se na concorrência regional para oferecer as melhores garantias jurídicas ao capital internacional, rebaixando todas as obrigações socioambientais. Este é exatamente o contrário do Vivir Bien, a não ser que este seja identificado com o padrão das classes dominantes da América Latina, em que o mais sofisticado padrão de consumo se combina ao trabalho doméstico barato, assentado em uma obscena concentração da riqueza. Em resumo, trata-se da reprodução do subdesenvolvimento, com rosto aymara.

É inegável que a Bolívia mudou nos últimos dez anos. Os viajantes já não encontram as tortuosas estradas esburacadas que atolavam sob chuva, e o país deixou de ser um destino barato. A economia se monetarizou, há indígenas e mulheres no poder, e se nota mais consumo. Mas também se nota mais abandono e mais violência.

Mais "moderno", o país parece deixar de ser a sociedad abigarrada13, analisada por Zavaleta Mercado, mas não em prol de uma nação soberana integrada em torno de um mercado interno, como pretendeu o nacionalismo revolucionário, ou mediante a convivência equânime de diversas visões de mundo, como desejou o plurinacionalismo. É o modo de produção capitalista subsumindo os modos de vida comunitários no bojo de um projeto que reedita o estilo político do velho MNR, em que o poder rapidamente se tornou um fim em si.

O fato de que uma parcela significativa da esquerda internacional ainda identifique este governo como progressista, enseja reflexão. Descartando a barreira da desinformação, que não é menor, há os reféns daquilo que em inglês se conhece como wishful thinking - acreditar no que se gostaria, e não no que se vê. Porém, muitos apoiam o governo baseado em considerações geopolíticas que abstraem a dinâmica da luta de clas-
12. transitar de la revolución democrática y cultural a la revolución económica y social, en un proceso que permita iniciar la construcción del socialismo comunitario bajo el paradigma del Vivir Bien.

13. Expressão consagrada nas ciências sociais bolivianas e de difícil tradução, refere-se ao padrão compósito e segregado de estratificação social do país, que aparta brancos de indígenas. 
ses no país (BORÓN, 2016), ou raciocínios binários ponderando que as alternativas seriam piores, prática conivente com a ideologia do TINA (There is no alternative). É preciso lembrar que a constatação de relações conturbadas com os Estados Unidos é inconclusiva: a lógica de que o inimigo do meu inimigo é meu amigo, levaria a esquerda a apoiar regimes repressivos na Síria e no Irã.

No proceso de cambio boliviano, o aspecto criativo das tensões do presente aludidas por Garcia Linera, só sobrevive como ideologia. Diante desta realidade, a reação do governo boliviano à deposição de Dilma Roussef em 2016, ao contrário de expressar um compromisso com a democracia e a soberania popular, que na Bolívia não há, é sugestiva da natureza dos nexos entre os governos do MAS e do PT no Brasil. A análise interna do governo Morales sugere que as afinidades entre estes governos estavam antes referidas a um projeto de poder, expressado respectivamente pelo MAS e pelo PT, do que por um projeto popular, que em ambos casos, é difícil comprovar. No caso petista, interessava preservar a Bolívia como um território de negócios cativo sob sua influência política, em consonância com o desígnio de afirmar-se como global player. Do ponto de vista boliviano, o país recebeu investimentos desejados e uma importante cobertura política para sustentar sua imagem internacional no campo da esquerda.

Em última análise, esta aproximação mediada por nexos mercantis, entre governos que tem como horizonte uma soberania restrita à inserção subordinada na divisão internacional do trabalho, e uma igualdade limitada à distribuição dos excedentes advindos da exportação primária nos momentos de expansão, é reveladora do alcance e dos limites da onda progressista sul-americana, que ora se esgota.

Referências

ACOSTA, Alberto. O bem viver. São Paulo: Elefante, 2016.

ALBO, Xavier. Algunos de nuestros desafíos ambientales. Pagina Siete, La Paz, abril de 2015, p. 20.

ALMARAZ, Alejandro. La frustración agraria. Pagina Siete, La Paz, abril de 2015, p. 23.

ARCHONDO, Rafael. 'El periodismo en la era Evo Morales. Pagina Siete, La Paz, abril de 2015, p. 34.

ARGUedAS, Alcides. Pueblo enfermo. La Paz: Ercilla, 1910 (1937).

ARZE VARGAS, Carlos; ESPADA GUZMÁN, Juan Luis; POVEDA, Juan Carlos. Gasolinazo: subvención popular al Estado y a las petroleras. La Paz: Cedla, 2011.

ARZE VARGAS, Carlos; GÓMEZ, Javier. Las contradictorias nociones del Vivir Bien y las estrategias para alcanzarlo. In: LANDER, Edgardo; ARZE, Carlos; GÓMEZ, Javier; OSPINA, Pablo; ÁLVAREZ, Víctor. Promesas en su laberinto. Cambios y continuidades en los gobienros progresistas de América Latina. La Paz: IEE, CEDLA, CIM, 2013.

BOFF, Leonardo. 'Os equívocos do PT e o sonho de Lula'. Fevereiro de 2016. Disponível em: $<$ https://leonardoboff.wordpress.com/2016/02/06/os-equivocos-do-pt-e-o-sonho-de-lula/>. Acesso em 12/2/2016.

BORÓN, Atilio. El no nace en Washington. La Jornada, 11 de fevereiro de 2016. Disponível em <http://www.jornada.unam.mx/2016/02/11/opinion/031a1mun\#texto $>$. Acesso em 13 de fevereiro de 2016.

CONDORI, Ivan. La Cumbre Agropecuaria definirá lineamientos para la Agenda 2025. La razón, La Paz, 5/4/2015. Disponível em: <http://www.la-razon.com/economia/Cumbre-Agropecuaria-definira-lineamientos-Agenda_0_2246775352.html>. Acesso em 8/2/2016. 
CRABTREE, John. Patterns of protest. Politics and social movements in Bolivia. London: Latin American Bureau, 2005.

DANGL, Benjamin. El precio del fuego. Las luchas por los recursos naturales y los movimientos sociales en Bolivia. La Paz: Plural, 2009.

FUNDACIÓN TIERRA. Marcha indígena por el TIPNIS. La lucha en defensa de los territorios. La Paz, Fundación Tierra, 2012.

GANDARILLAS, Marco; RODRÍGUEZ Cáceres, Gustavo. Mitos de la inversión extranjera. El caso de los hidrocarburos en Bolívia. Cochabamba: CEDIB, sem data.

GARCÍA LINERA, Álvaro. Geopolítica de la Amazonía. Poder hacendal-patrimonial y acumulación capitalista. La Paz: Vicepresidencia, 2013c.

GARCÍA LINERA, Álvaro. El Capitalismo Andino Amazonico. Le monde diplomatique, Santiago, janeiro de 2006a. Disponível em: http://www.lemondediplomatique.cl/El-capitalismo-andino-amazonico.html. Acesso em 6/2/2016.

GARCÍA LINERA, Álvaro. El evismo: lo nacional popular en acción. Observatorio Social de America Latina, año VI, no. 19. CLACSO, Consejo Latinoamericano de Ciencias Sociales, Buenos Aires, Argentina: Argentina. julio. 2006b.

GARCÍA LINERA, Álvaro. El 'oenegismo’, enfermedad infantil del derechismo. La Paz: Vicepresidencia, 2013a.

GARCÍA LINERA, Álvaro. Las empresas del Estado. Patrimonio colectivo del pueblo boliviano. La Paz: Vicepresidencia, 2013b.

GARCÍA LINERA, Álvaro. Las tensiones creativas de la revolución. La Paz: Vicepresidencia, 2014 (2011).

GARCÍA LINERA, Álvaro. Socialismo Comunitario. Un horizonte de época. La Paz: Vicepresidencia, 2015.

HYLTON, Forrest; THOMSON, Sinclair. Revolutionary horizons. Past and present in Bolivian politics. London: Verso, 2007.

LOAYZA BUENO, Rafael. Eje del MAS. Ideología, representación social y mediación en Evo Morales Ayma. La Paz: Konrad Adenauer, 2011.

MIRANDA, Boris. Bolivia: el millonario caso de corrupción que involucra a exministros, parlamentarios y dirigentes del partido de Evo Morales. BBC, dez 2015. Disponível em <http:// www.bbc.com/mundo/noticias/2015/12/151205_millonario_escandalo_corrupcion_partido_ evo_morales_bm>. Acesso em 6/2/2016.

MOLINA, Fernado. Donde el "proceso de cambio" choca con el subdesarollo. Pagina Siete, La Paz, abril de 2015, p. 27.

ORMACHEA, Enrique S.; RAMIREZ, Nilton. Políticas agrarias del Gobierno del MAS o la agenda del 'poder empresarial-hacendal'. La Paz: Cedla, 2013.

RADA VÉLEZ, Alfredo. 'En defensa de los movimientos sociales'. Pagina Siete, La Paz, abril de 2015 , p. 4.

REQUENA, Cecília. El Vivir Bien y sus malestares. Pagina Siete, La Paz, abril de 2015, p. 21.

RIVERA CUSICANQUI, Silvia. Oprimidos pero no vencidos: luchas del campesinado aymara y quechwa de Bolivia, 1900-1980. La Paz: Hisbol-CSUTCB, 1984.

RIVERA CUSICANQUI, Silvia. Mito y desarrollo en Bolivia. El giro colonial del gobierno del MAS. La Paz: Plural, 2013.

SCHAVELZON, Salvador. Plurinacionalidad y Vivir Bien/ Buen Vivir. Dos conceptos leídos desde Bolivia y Ecuador post-constituyentes. Quito: Abya Yala/Clacso, 2015.

SILVA, Fabrício Pereira da. Equilíbrios precários: a trajetória do movimento ao socialismo e seus dilemas. In: DOMINGUES, José Maurício et al. A Bolívia no espelho do futuro. Belo Horizonte: UFMG, 2009.

SORUCO, Ximena (cord.). Los barones del Oriente. El poder en Santa Cruz ayer y hoy. Santa Cruz, Fundación Tierra, 2008

STEFANONI, Pablo; ALTO, Hervé do. Evo Morales: de la coca al palacio. Una oportunidad para la izquierda indígena. Bolivia: Malatesta, 2014.

URIOSTE, Miguel. La marginalización de la agricultura campesina e indígena. Pagina Siete, La Paz, 2015, p. 22. 
URQUIDI, Vivian. Movimento cocaleiro na Bolívia. São Paulo: Hucitec, 2007.

WEBBER, Jeffery. From Left-Indigenous Insurrection to Reconstituted Neoliberalism in Bolivia: Political Economy, Indigenous Liberation, and Class Struggle, 2000-2011. IN:

WEBBER, Jeffery; CARR, Barry. The new Latin American left. Cracks in the Empire. Lanham: Rowman \& Littlefield Publishers, Inc., 2013.

ZAVALETA MERCADO, Rene. Lo nacional-popular en Bolivia. La Paz: Plural, 2008 (1986).

ZAVALETA MERCADO, Rene. Clases sociales y conocimiento. La Paz: Amigos del libro, 1988.

Entrevistas realizadas entre 5 e 15 de julho de 2015 em Santa Cruz, Cochabamba e La Paz.

ALMARAZ, Alejandro. Ex vice-ministro de terras do governo Evo Morales (2006-2010).

ÁVILA, Hernán. Diretor do Centro de Estudios Jurídicos e Investigación Social (CEJIS)

CAMPERO, Ariana. Médica, Ministra da Saúde.

CAMPOS, Isau; TOSITO, Franklin; ROMERO Zolando. Dirigentes da Central Obrera Departamental.

CHÁVEZ, Adolfo. Dirigente da CIDOB.

ESCOBAR, Sílvia. Economista e pesquisadora Centro de Estudios para el Desarrollo Laboral y Agrario (CEDLA)

GANDARILLAS, Marco Antonio. Diretor do Centro de Documentación e Información Bolívia (CEDIB).

MÉNDEZ, Fernando. Coordenador da Casa del ALBA - Alianza Boliviana para los Pueblos de Nuestra América Latina, em Cochabamba.

PAZ Sarela. Pesquisadora, referência em assuntos relacionados ao TIPNIS.

PEREDO, Osvaldo "Chato". ex-líder guerrilheiro e ex-vereador pelo MAS em Santa Cruz.

PEREZ PEÑA, Miguel Angel. Analista de relações institucionais da Petrobras Bolívia S.A.

RIBERA ARISMENDI. Marco Antonio. Diretor da Liga de defesa del meio ambiente (LIDEMA)

SALLARI, Andrés; VÁZQUEZ, Mariano. Jornalistas do canal estatal ABYA YALA.

SARAVIA, Ramiro. Red Tinku.

SAUCEDO, Erwin. Deputado federal por duas vezes, ministro da saúde do governo de transição e professor de saúde pública.

VADILLO, Alcides. Advogado, diretor da Fundación Tierra, trabalhou no Ministério de Reforma Agraria.

VILLANUEVA, Amaru. Diretor do Centro de Investigaciones Sociales de la Vicepresidencia (CIS).

VILLEGAS, Pablo. Pesquisador do CEDIB. 